\title{
Developing a Nuclear Global Health Workforce Amid the Increasing Threat of a Nuclear Crisis
}

\author{
Frederick M. Burkle, Jr, MD, MPH, DTM, FAAP, FACEP; Cham E. Dallas, MS, PhD
}

\section{ABSTRACT}

This study argues that any nuclear weapon exchange or major nuclear plant meltdown, in the categories of human systems failure and conflict-based crises, will immediately provoke an unprecedented public health emergency of international concern. Notwithstanding nuclear triage and management plans and technical monitoring standards within the International Atomic Energy Agency and the World Health Organization (WHO), the capacity to rapidly deploy a robust professional workforce with the internal coordination and collaboration capabilities required for large-scale nuclear crises is profoundly lacking. A similar dilemma, evident in the early stages of the Ebola epidemic, was eventually managed by using worldwide infectious disease experts from the Global Outbreak Alert and Response Network and multiple multidisciplinary WHOsupported foreign medical teams. This success has led the WHO to propose the development of a Global Health Workforce. A strategic format is proposed for nuclear preparedness and response that builds and expands on the current model for infectious disease outbreak currently under consideration. This study proposes the inclusion of a nuclear global health workforce under the technical expertise of the International Atomic Energy Agency and WHO's Radiation Emergency Medical Preparedness and Assistance Network leadership and supported by the International Health Regulations Treaty. Rationales are set forth for the development, structure, and function of a nuclear workforce based on health outcomes research that define the unique health, health systems, and public health challenges of a nuclear crisis. Recent research supports that life-saving opportunities are possible, but only if a rapidly deployed and robust multidisciplinary response component exists. (Disaster Med Public Health Preparedness. 2016;10:129-144)

Key Words: public health, nuclear weapons, international agencies, nuclear disasters, foreign medical teams

If the larger, more threatening issue is not to be openly acknowledged and confronted, why worry about lesser problems?

- Rita R. Rogers, MD, on denial of the nuclear threat, Psychosocial Aspects of Nuclear

Development

$\mathrm{T}$ he Ebola crisis in West Africa is a wake-up call for how the world defines global health and global health security. Despite a 2005 post-SARS robust International Health Regulations Treaty (IHR) that gave unprecedented authority to the World Health Organization (WHO) to rapidly deal with any future epidemics or pandemics, the subsequent resulting preparedness capability quickly diminished before the Ebola tragedy because of major cuts in funding, staffing, and resources. A saving grace in this tragedy was the manner in which the Global Outbreak Alert and Response Network (GOARN), ${ }^{1}$ foreign medical teams (FMTs), ${ }^{2}$ and international nongovernmental organizations (INGOs) coordinated with available WHO resources for the common good to address what was declared a public health emergency of international concern (PHEIC). ${ }^{3}$ The WHO, under the IHR, recognizes that PHEICs require "maximum measures...tailored to the actual threat faced" internationally to control the crisis. ${ }^{4}$ Unfortunately, the Ebola crisis experience underscored many unresolved challenges facing the global community in how they will address PHEICs in the future. Of the many proposals placed before the WHO to be discussed and debated include one for the development of a Global Health Emergency Workforce, ${ }^{5,6}$

During the Ebola tragedy, an unprecedented global workforce was mobilized to provide dire health solutions while foreign-led governmental and military resources restored the public health infrastructure and protections that were equally necessary to counter the epidemic spread. Understandably, there is significant concern over the capacity and capability of global resources to duplicate the efforts seen in West Africa let alone organize, resource, and sustain these resources to thwart any future global PHEICs, one of the foremost being the egregious prospect of a major nuclear catastrophe.

This study dissects what is known of the changing face of credible nuclear threats and argues for the immediate formation of a nuclear global health 
workforce in support of the technical expertise of the International Atomic Energy Agency (IAEA) and WHO's Radiation Emergency Medical Preparedness and Assistance Network (REMPAN) leadership in utilizing frameworks like GOARN and the expanding network of FMTs to pattern competency-based professionalization, education, training, and response criteria for all PHEICs. None of these challenges can afford a weak IHR, WHO, or international organizations that deal specifically with nuclear agendas.

\section{THE PROBLEM}

Crises on a world scale can be defined as natural, human systems failure, or conflict-based. ${ }^{7}$ Operationally, what defines the criticality and the need for external and often global response is the recognition that many crises adversely impact the public health system, its protective infrastructure (ie, water, sanitation, shelter, food, fuel and energy-yielding infrastructures, and health care access and availability), and prevention programs (eg, vaccinations, maternal and child health, mental health). ${ }^{8,9}$ Characteristically, crises result in massive direct mortality and morbidity rates but over time even more indirect consequences are seen as the preventable public health infrastructure breaks down, human insecurity becomes more prevalent, and large numbers of the at-risk populations flee. ${ }^{8,10}$ Indeed, indirect consequences often represent $60 \%$ to $90 \%$ of the total mortality and morbidity, especially in large-scale and prolonged conflicts and wars. ${ }^{7,11}$ Once the catastrophic event occurs, goals must shift to ensure optimal mitigation of a rise in indirect mortality and morbidity through provisions of directed prevention and preparedness actions and resources.

Historically, since the end of World War II and the passage of the United Nations (UN) charter, about every 2 decades the reasons leading up to declared humanitarian crises and how the world responds to them have dramatically changed. ${ }^{12}$ The Marshall Plan and similar infrastructure efforts helped to restore the public health protections immediately after World War II as did aid organizations guided by the newly minted 4th Geneva Convention and its subsequent protocols that codified civilian and humanitarian protections. However, over the decades of the Cold War in many countries, especially under the Soviet Block, restoration remained slow with painful public health consequences for their populations. The end of the Cold War in the 1990s ushered in an era where nation-states, many formerly under the Soviet Union, suffered internal public health and humanitarian crises resulting in wanton violations of international humanitarian law, massive corruption, and suspension of the rule of law resulting in massacres and genocide. So-called "unconventional" warfare followed, characterized by large numbers of internally displaced populations fleeing prolonged intrastate conflicts where the Laws of War and IHL struggled to be relevant. By the turn of this century, nondeclared unconventional warfare-like social media-driven nation-state revolts and the rise of nonstate actors personified by ISIS, al-Qaida, their affiliates, and small group jihadistshave become the new norm where prolonged conflict, infrastructure destruction, and chronic insecurity have left major areas of the world with few viable health systems and public health protections.

As we enter the 21 st century, the term mega-catastrophe is now being used to describe extreme events that are global in scale with outcomes that are difficult or even impossible to reverse. ${ }^{12}$ Such events are distinguished from previous disaster taxonomy by increasing frequency and severity of devastating effects on large human populations and the environment, including rapid unsustainable urbanization, emerging biodiversity crises, issues regarding climate extremes, and the impending realities of major resource scarcities. ${ }^{12}$ These have the sobering prospect of being played out in a desperate competition for water, energy, land, and food. Infectious disease pandemics, epidemics, and increasing outbreaks are often rekindled and hastened by increasingly dense populations and scarce or collapsed basic public health protections. Regrettably, they also represent tragedies in which the WHO Regional Offices and the international community face inadequate funding, staffing, and resources, risking a weakened or delayed response capacity making the original intent of the IHR in doubt.

We emphasize that any nuclear weapon exchange or major nuclear plant meltdown, in the categories of human systems failure and conflict-based crises, will immediately provoke an unprecedented PHEIC. Nuclear detonations in urban areas in particular will not only destroy the existing public health protections but will, most likely, make it extremely difficult to respond, recover, and rehabilitate them. Massive evacuations of survivors will be necessary, leaving large swaths of territory uninhabitable for decades, with catastrophic impacts on humans, the economy, and the environment. Mental health and societal chaos would rapidly ensue and result in highly destabilizing ripple effects throughout both the region and globally. The nascent nuclear response organizations will find themselves beset with a similar, but even more grievous, dilemma than that which confronted responders during the rapidly spreading Ebola epidemic.

\section{NUCLEAR PROLIFERATION Nuclear Weaponry}

At the end of the Cold War there were over 52,000 nuclear warheads, $97 \%$ belonging to the United States and the dissolving Soviet Union. ${ }^{13}$ Today, there are 9 nations (Table 1) that are known to possess approximately 16,350 nuclear weapons. Fortunately, the United States and the Soviet Union (now Russia) have dramatically decreased the number of active nuclear weapons, with far fewer weapons on "standby" to be used on rapid notice. It must be noted, however, that many warhead "cores" are kept in the United States and Russia in stockpiles, ready to be reactivated onto missile warheads or 


\section{TABLE 1}

\begin{tabular}{|c|c|c|c|c|}
\hline \multicolumn{5}{|c|}{ Nuclear Weapons Worldwide } \\
\hline \multicolumn{5}{|c|}{ Nations with nuclear weapons } \\
\hline Russia & United & China & Pakistan & North Korea \\
\hline United States & Kingdom France & India & Israel & \\
\hline \multicolumn{5}{|c|}{ Nations hosting nuclear weapons on their soil } \\
\hline Belgium & Italy & Turkey & & \\
\hline Germany & Netherlands & & & \\
\hline \multicolumn{5}{|c|}{ Nations in nuclear alliances } \\
\hline Albania & Czech & Iceland & Norway & Slovenia \\
\hline Australia & Denmark & Japan & Poland & South Korea \\
\hline Bulgaria & Estonia & Latvia & Portugal & Spain \\
\hline Canada & Greece & Lithuania & Romania & \\
\hline Croatia & Hungary & Luxembourg & Slovakia & \\
\hline \multicolumn{5}{|c|}{ Nations with Advanced Nuclear Material for Nuclear Weapons } \\
\hline Japan & Iran & & & \\
\hline
\end{tabular}

bombs if their leaders warrant a massive rearmament is justified. The recent addition of 40 new intercontinental ballistic missiles by Russia illustrates this danger, as they are taking scores of nuclear warheads out of storage and putting them back on new missiles. Although the total number of warheads, the "size" of their nuclear arsenal, stays the same, the relative danger of their use has increased dramatically. This also reflects a disturbing reversal of the trend between the United States and Russia that had existed of the gradual decrease in both the number of warheads in the arsenal (Figure 1) and the number of "active" warheads on missiles and in devices ready for detonation (Figure 2). The United States is now the only nation that is no longer "modernizing" its nuclear arsenal, by either increasing weapon numbers or their deployment capability.

China, France, Russia, the United Kingdom, and the United States are officially recognized as possessing nuclear weapons by the Nonproliferation Treaty (NPT). The NPT, which entered into force as a Treaty in 1970, grew to 190 members including 5 nuclear-weapon nations. India, Israel, and Pakistan are nuclear powers that never joined the NPT. ${ }^{14}$ North Korea, which has the material to produce a relatively small nuclear weapon arsenal, announced its withdrawal from the NPT in 2003 and tested nuclear devices. ${ }^{14}$ Uncertainty persists about how many additional nuclear devices North Korea has assembled beyond those it has tested, possibly up to 20. Several more carry out secret programs or aspire to create nuclear weapons. There are nations hosting nuclear weapons on their soil and also nations that rely on a nuclear alliance with the United States for their security (Table 1). ${ }^{14,15}$ The Federation of American Scientists in 2014 reported that at least 40 nations possess nuclear power or research reactors capable of being diverted for weapons production, several with the ability to make a weapon in a matter of months. Of concern for the near future, several other nations are believed to possess significant nuclear munitions and the capability to manufacture significant numbers of nuclear warheads relatively quickly once they choose to do so, such as Iran and Japan (Table 1). ${ }^{15}$

\section{FIGURE}

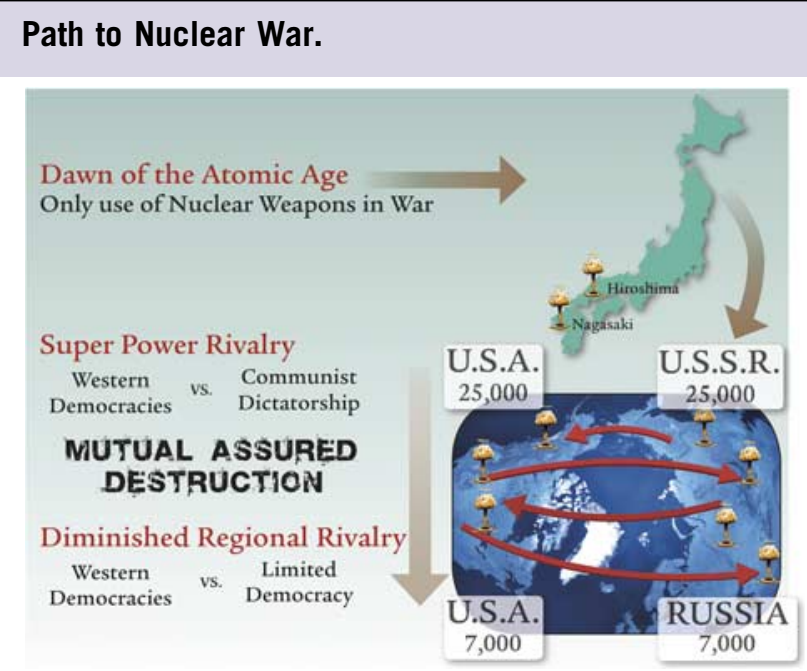

The historical progression of the likelihood of the medical and public health consequences of nuclear war. Starting with the only use of nuclear weapons in war at the end of World War II, the development of the established pattern of mutual assured destruction between powerful nuclear weapon states is shown, along with the relative decline over time in the massive nuclear arsenals.

Regional nuclear arms races are very worrisome between antagonistic neighbors with whom previous and repeated nonnuclear conflicts are now capable of being fought with nuclear weapons. Claiming its nuclear program was for peaceful purposes, India first tested a nuclear explosive device in 1974. That test spurred Pakistan to ramp up work on its secret nuclear weapons program. India and Pakistan both publicly demonstrated their nuclear weapon capabilities with a round of tit-for-tat nuclear tests in May 1998. The West fears politically unstable Pakistan and its ability to secure its steadily increasing nuclear weapons (5-10 new weapons every year), which are alleged to be stored on military bases across the country, making the theft of a weapon a possibility. Israel has not publicly conducted a nuclear test, does not admit to or deny having nuclear weapons, and states that it will not be the first to introduce nuclear weapons in the Middle East. Nevertheless, Israel is universally believed to possess nuclear arms, including the larger thermonuclear devices, although it is unclear how many weapons it possesses. ${ }^{14}$ Fissile material is the key element for making nuclear weapons. India and Israel are believed to use plutonium in their weapons, whereas Pakistan is thought to use highly enriched uranium. ${ }^{16}$

On the "positive" side, there has been some progress on the reduction of the number of nations possessing nuclear weapons. Belarus, Kazakhstan, and Ukraine inherited nuclear weapons following the Soviet Union's 1991 Cold War collapse but returned them to Russia and joined the NPT as non-nuclear-weapon nations. In the 1970s and 1980s, South Africa secretly developed 7 nuclear warheads. At the end of the Cold War, the weapons were dismantled and South 


\section{FIGURE 2}

\section{Increasing Risk.}

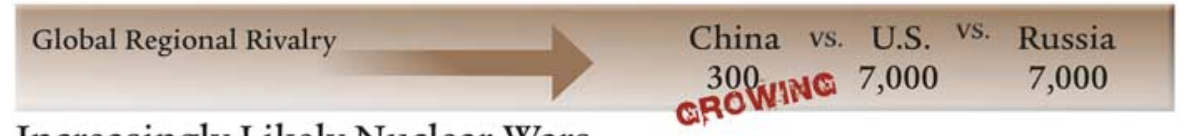

Increasingly Likely Nuclear Wars

\begin{tabular}{|c|c|}
\hline $\begin{array}{l}\text { Long-term } \\
\text { Religious Hatred }\end{array}$ & $\begin{array}{l}\text { India vs. Pakistan } \\
\text { 150WHAG } 120 \text { WRAG } \\
\text { GROWOWHA }\end{array}$ \\
\hline $\begin{array}{l}\text { Long-term } \\
\text { Religious Hatred }\end{array}$ & $\begin{array}{c}\text { Israel vs. Pakistan, Iran } \\
200 \\
120 \text { GROW }\end{array}$ \\
\hline $\begin{array}{l}\text { Unstable } \\
\text { Dictatorship }\end{array}$ & $\begin{array}{l}\text { th Korea vs. U.S., So. Korea, Japan } \\
20 \text { OWHNG } \quad 7,000\end{array}$ \\
\hline
\end{tabular}

Immediate Future

Long-term
Religious Hatred $\begin{gathered}\text { Sunni vs. Shiite } \\ \text { GROWING GROWING }\end{gathered}$

Progression of the threat of nuclear war from traditional national rivals to a steadily increasing risk by smaller, less stable nation states and now the primary importance of religiously motivated groups. On the right the potential adversaries are shown, with relative sizes of available nuclear weapon arsenals, and in particular the fact that most of these nuclear arsenals are steadily growing. On the left are the motivations for conflict, showing the progression from large nations with traditional global and regional rivalries to regional conflicts with a marked trend toward long-term, intense religious animosities and unstable dictatorships.

Africa joined the NPT in $1991 .{ }^{14}$ Iraq had an active nuclear weapons program prior to the 1991 Persian Gulf War but was forced to verifiably dismantle it under the supervision of UN inspectors. ${ }^{17}$ Libya voluntarily renounced its secret nuclear weapon development efforts in December 2003 under pressure from the United States. Argentina, Brazil, South Korea, and Taiwan have also shelved their nuclear weapons programs for the present. ${ }^{14}$

Arguably, the Middle East is a cauldron of potential nuclear threats as the distances between antagonistic nations is a matter of minutes by ballistic missile. Iran, Libya, and Syria pursued secret nuclear activities in violation of the treaty's terms. Syria, with the help of North Korea, secretly began to develop a weapons reactor but Israel's military bombed it in 2007. Iran has been steadily increasing its significant stockpiles of enriched uranium to the $20 \%$ level, with the capability to increase this large stockpile to weapons grade material $(>90 \%)$ in a relatively short time frame. ${ }^{14,18}$ The IAEA, the institution charged with verifying that states are not illicitly building nuclear weapons, concluded since 2003 that Iran has undertaken covert nuclear activities to establish the capacity to indigenously produce fissile material. Secret facilities for these activities have been repeatedly discovered in Iran, and the IAEA is continuing its investigation and monitoring of Tehran's nuclear program. ${ }^{18}$

Other significant concerns are the threats of a dirty bomb (explosive device encased in radioactive materials), crude radioactive dispersal devices, and "lost" former Soviet nuclear materials from the infamous "suitcase nukes."19,20 Although dirty bombs are not immediately lethal (other than the conventional explosives) and generally are not expected to result in significant radiation-induced casualties, it is likely that the use of a dirty bomb or some other dispersal of radioactive materials will result in immediate and significant disruption from mass panic and terror. The IAEA reports that "about 140 cases of missing or unauthorized use of nuclear and radioactive material" were reported to the UN atomic agency in 2013, adding that "any loss or theft of highly enriched uranium, plutonium or different types of radioactive sources is potentially serious" and "can be used in radioactive dispersal devices." This includes sources "found in hospitals, factories or other places that may not be very well protected." 21 While it is assumed that nonstate terrorists lack capacity to develop a nuclear weapon, they have shown both the capacity and considerable interest in developing a dirty bomb from radioactive materials. Whether that capacity and capability is increasing or not is unknown.

The authors conclude that the increasing spread of nuclear weapons to more nations, the increased volatility of international relations, the developing technological sophistication among terrorist groups, the increasing global availability and distribution of radioactive materials, and the increasingly hostile accompanying rhetoric has significantly escalated the risk for a nuclear exchange and its devastating impact on medicine and public health worldwide. 


\section{Nuclear Power Plants}

Nuclear energy facilities are expanding worldwide. At the moment, there are 388 operating reactors in operation in 31 countries; however, this represents 50 fewer than at the peak in 2002. Belgium, Germany, Switzerland, and Taiwan are phasing out nuclear power and Egypt, Italy, Jordon, Kuwait, and Thailand have decided not to engage or re-engage in nuclear power programs. Construction costs are rapidly rising. ${ }^{22}$ Most of the world's power reactors are edging toward old age, so even if modest short-term growth is achieved, significant new reactor construction will be required in coming decades just to replace permanent reactor shut downs. The average age of the world's operating nuclear reactor fleet continues to increase and by mid-2014 stood at 28.5 years. Over 170 units (44\%) have operated for 30 years or more; of those units, 39 have run for over 40 years. ${ }^{22}$

Following the earthquake and tsunami in Japan in 2011 and the ongoing problems at the Fukushima nuclear power complex, the level of preparation and readiness for impact from natural disasters is a rising global concern. Seismologists predict that another major earthquake in Japan, this time in Tokyo, is likely in the next 10 years. ${ }^{23}$ Despite grievous failures in the management of the immediate Fukushima crisis and in its recovery process, Japan is still significantly dependent on nuclear power owing to its enormous previous investment in this infrastructure and otherwise complete dependence on imported fossil fuels. ${ }^{24}$ Additional costs arising from upgrading and back-fitting measures in many countries following the lessons of the Fukushima crisis remain uncertain and vary widely according to the requirements of the safety authorities in various countries.

However, there is continued (and even renewed) interest in nuclear reactor power production in the United States and elsewhere as coal-generated electricity is now increasingly losing momentum in the wake of climate concerns. ${ }^{25}$ It cannot be denied that much of the avowed interest in nuclear reactors for power generation has been in the past and is also today tied to the secret desire to also develop nuclear weapons. A number of countries are actively constructing power plants for the first time (Belarus, United Arab Emirates, Lithuania, Turkey, Bangladesh, Jordan, Poland, and Vietnam). However, many countries have rolled back "previously ambitious plans primarily due to finances and/or concerns over political support," especially in Europe. ${ }^{22}$

\section{FACTORS INFLUENCING NUCLEAR RISK}

Several significant nuclear plant and radiation-related device accidents have demonstrated the potential hazards of the release of large amounts of radioactive materials into the environment, for example, the huge radioactive material and chemical explosion and large-scale radiation dispersion at Chelyabinsk Mayak in 1957; the nonnuclear explosion and fire at the large Chernobyl nuclear reactor complex in the
Soviet Union that resulted in the very large airborne dispersion of radiation in 1986; the Goiania, Brazil, high-dose radioactive source release of 1987; and the Fukushima reactor core and spent fuel rod meltdown and large-scale radiation dispersion in contaminated water in 2011. Additional factors unique to concerns over nuclear risk fall into 3 categories: (1) deceptive governmental and military practices, (2) religious and culturally driven motivations, and (3) collective denial.

\section{Deceptive Governmental and Military Practices}

A major reason for risk expansion lies in the disturbing pattern that began immediately after World War II where, despite robust assurances to the contrary, nuclear "secrets" have always rapidly spread. Cold War tensions and paranoia were largely driven by the fear of nuclear war, yet the strategic doctrine called mutually assured destruction (MAD) was dependent on mutual knowledge that the nuclear arsenals of the United States and the Soviet Union were sufficiently capable of destroying the other side. ${ }^{26}$ Proponents argued that since launching a nuclear attack was akin to signing your own country's death warrant, this fear ultimately served as a deterrent to nuclear aggression. In retrospect, while apparently successful, this Cold War deterrent was an extremely risky policy. ${ }^{27,28}$ For instance, during the Cold War both American and British military field commanders had authorization to use tactical nuclear weapons (smaller warheads for use on the battlefield). Since Soviet orders determined that any nuclear attack on its forces legitimized a full-scale nuclear response, MAD could have been easily triggered in this and a variety of other events. During the 1962 Cuban missile crisis, the United States was surprised that the Soviets had already deployed nuclear weapons to Cuba and that local commanders had authority to use them. ${ }^{29}$ The 1967 JASON Committee report contemplated the "appeal" of using tactical nuclear weapons in Vietnam. ${ }^{30}$ a report that supported the premise that the post-World War II use of nuclear weapons was slowly becoming "normalized" in military and political culture. ${ }^{31}$ While fears dramatically subsided in the 1990s, similar rhetoric escalating between Russia and the West recently has again fueled fears and paranoia.

Regional hatreds generated and sustained over a thousand years, like that between the Hindus of India and the Muslims of Pakistan, led locally to a "series of nuclear threats" in South Asia in the late 1990s, and then dramatically accelerated global nuclear proliferation when a noted Pakistan nuclear scientist sold centrifuge technology to North Korea, Iran, and Libya. ${ }^{32}$ Sagan $^{33}$ argues persuasively with these incidents and an increasing number of others that the danger of the actual use of nuclear weapons somewhere in the world is mounting. Governments with nuclear weapon capability believe that shielding themselves with their nuclear arsenals will allow them to engage more safely in other nonnuclear aggressive actions and deter others from competing with them 
due to their nuclear "strength." ${ }^{33}$ Burkle $^{34}$ argues that traditional diplomatic negotiations are becoming useless with many despots suffering severe narcissistic sociopathy as they fill the power void left from the dissolution of the Cold War. They continue to thrive on prolonged intrastate conflicts, some supporting major terrorist cell leaders. ${ }^{34}$ Nothing is more dangerous than an ego-wounded narcissist when his or her power is challenged, as we have recently witnessed in Syria and North Korea, than perhaps a nuclear-armed narcissist.

\section{Religious and Culturally Driven Motivations}

Scientists in the Armed Forces Countermeasures Programs attribute increased probability for acute radiation exposures a "rising concern" based on changing social and political climates. They see a greater threat to "detonation of nuclear weapons by terrorists, sabotage of nuclear facilities, dispersal and exposure to radioactive materials and accidents." ${ }^{35}$ Today, the capabilities of suicide bombers has increased, especially since 9/11. Motives for suicide attacks include "religious beliefs, nationalistic ideologies, obedience to charismatic and authoritarian leaders, or desire for political change." ${ }^{36}$ In a 2013 "Victory Day" parade, North Korea displayed a truckload of soldiers "each strapped into a chest pack festooned with black and yellow radiation symbol."37 North Korea has amply demonstrated that a nation that cannot feed its own people can still acquire nuclear weapons, using threats of a nuclear attack as their only negotiating leverage.

Perry ${ }^{38}$ reminds us that "some of the most appalling atrocities in history have not been rooted in religion per se but rather in racial or class hatred." In modern times, however, humanitarian efforts are more commonly tied to patterns and consequences of religious-based violence of "intense and ruthless character." 38 Wars in the name of religion have dominated the last 3 decades with possession and use of advanced weaponry now advancing to nuclear weapon arsenals. This ominous combination is profound between Pakistan and India, Israel and its Islamic neighbors, the new nuclear arms race between the Sunni and Shi'a branches of Islam, and other ethnic populations who, except for religious beliefs, share strong undeniable cultural identity and similar genetic heritage. ${ }^{39}$

\section{Collective Denial}

Denial is one of our most powerful defense mechanisms designed to protect the ego (and collectively shared mankind) from uncomfortable but real issues or events that we cannot cope with. Despite overwhelming existence that something is true, denial will reject its existence. There is a blockage of awareness and the potential emotional impact of what we don't want to know, think about, or feel. Frank ${ }^{40}$ emphasizes that humans respond to events as they perceive them, not necessarily as events occur in reality. The human race has always "conferred weapon's strength upon their possessors, both in appearance and in fact." 40 "The image of strength projected by a large stockpile of nonnuclear weapons was based on real strength; therefore it was realistic for individuals or national leaders to rely on weapons to reassure themselves, intimidate their actual or potential enemies, and hold the loyalty of their allies." ${ }^{40}$ Jenkins adds that "two-thirds of the present world population has never known a world which did not have poised nuclear weapons." He states "they are part of us and not perceived as a foreign body." Diplomatic efforts and agreements stress only "stabilization" and "diminution" of stockpiles. ${ }^{41}$ The destructive potential is "nearly incomprehensible and so overwhelming and personally threatening that we appreciate being denied the facts while allowing a policy of secrecy to enhance the natural tendency to deny the threat and a social system that routinely fails to address it." ${ }^{\prime 1}$

Despite this widespread denial, the perfect storm of total health management inadequacy will occur even for small nuclear weapon attacks. It is even more difficult to imagine (and for most it is difficult to face) what will occur if sizable nuclear weapon exchange took place. Yet, there has been for years, largely among diplomats and health care professionals, a poorly understood huge and collective atmosphere of denial surrounding the consequences of nuclear war. ${ }^{42}$ This occurs at the population level as massive denial. The predominance of technical jargon that exists aids denial by intellectualizing the consequences beyond the realm of popular understanding. Without clear answers or rebuttal, denial will, over time, become incorporated into religious and fantasy beliefs that provide and interpret meaning and reason to what are seen as inevitable catastrophic outcomes, especially to those perceived as being backed into a corner. Decision to use nuclear weapons by Iran remains the authority of the Ayatollah, the religious Supreme Leader of the Islamic Revolution. One is reminded of Fein, ${ }^{42}$ a physicist, who in 1981 gave little hope for nuclear reduction, making the case that the weapons hold society in thrall, having attained a sacred aura by their mystery and awesome capabilities, and as a sacred object were being developed with a kind of "religious fervor, in which the weapons were being worshipped," a view that might have applicability to the current Middle East arms race.

It is curious that among global health care providers there are not more references to the health catastrophe that would occur; this lack is symptomatic we believe of our own, and too often, pattern of denial. A consummate failure in diplomacy may occur if medicine and public health hesitates to inform the otherwise sacrosanct and impervious realm of politically focused conventional dialogue. Effective diplomacy surrounding nuclear deterrence is an exception to conventional dialogue; it must first reveal and stress, with transparency, the uncomfortable but accurate information of the consequences of such an event. With uncompromised cross-cultural, religious, and spiritually sensitive skill, efforts must be made to work toward replacing "extremism fantasy" with unvarnished truth and reason. ${ }^{43}$ 


\section{HEALTH OUTCOMES}

The most commonly recognized thread of illness, injury, and death seen in nuclear crises is acute radiation syndrome (ARS). Radiation overexposure induces ARS characterized by 3 consecutive subsyndromes: hematopoietic/bone marrow (30-70 rads, or 0.3-0.7 Gray), gastrointestinal (600-1000 rads, or 6-10 Grays), and cardiovascular/neurovascular (2000-5000 rads, or 20-50 Gray). ARS occurs from irradiation of the entire body, or most of it, by a high dose of penetrating radiation in a short period of time. The survival rate decreases with increasing dose. ${ }^{44-47}$ The 3 ARS subsyndromes have in common 4 clinical phases ${ }^{48}$ :

1. Prodromal: anorexia, nausea, vomiting, diarrhea;

2. Latent: asymptomatic recovery from phase 1 ;

3. Manifest illness: return of phase 1, infection, hemorrhage;

4. Recovery or death.

The higher the dose, the shorter the phases. The speed of onset of these phases can serve as an indicator of exposure dose. ARS with a good prognosis is characterized by vomiting that starts more than 4 hours after the incident, no significant changes in serial lymphocyte counts within 48 hours after the incident, and no other significant injuries. ARS with a bad prognosis is characterized by coma, seizures, vomiting more than 4 hours after the incident, a drop in serial lymphocyte count of greater than $50 \%$ within 48 hours, bloody vomitus or stool, and other serious injuries. ${ }^{47,48}$ Indeed, observation of the highly exposed Chernobyl workers revealed that those who had nausea and vomiting beginning in less than 30 minutes after the initiation of radiation exposure were unlikely to survive, whereas those who had prodromal symptoms that did not ensue until after 3.5 hours were more likely to be survivors. ${ }^{49}$

\section{Radiation Overexposure Accidents}

Relatively, the least damaging of events and health outcomes occur from radiation overexposure accidents. A 2015 study of 634 victims over a 33 -year period confirmed that most accidents occurred in the industrial sector and in medical practice through the use of radiation therapy or fluoroscopy. There were 190 deaths. $^{50}$ However, mass casualty from a similar radiation event could occur. Clinical symptoms varied from mild hematopoietic symptoms, local skin overexposures, local organ overexposures, and organ dysfunction resulting in permanent sterility, acute pneumonitis, renal failure, and cognitive defect. Over time these injuries often progressed due to inflammatory waves, inducing the spread of radionecrosis that requires long-term treatment. ${ }^{50} \mathrm{McGann}$ et $\mathrm{al}^{51}$ assert that radiologists, radiation oncologists, nuclear medicine specialists, and radiation safety officers have, by these experiences, become the de facto "subject matter experts." They are likely to be called upon to provide preparedness and planning expertise as well as clinical leadership and vital coordination and collaboration with other health specialists at the time of the overexposure crises. McGann et $\mathrm{al}^{51}$ caution that the current pool of radiologists will require education on increasing the skill sets and knowledge base of the types of major radiation incidents, contamination, detection, and ARS recognition and treatment options.

\section{Nuclear Plant Accidents and Meltdowns}

In the Chernobyl nuclear catastrophe, the badly designed and managed nuclear reactor led to a complete meltdown of the reactor core, resulting in 10-day-long emission of radionuclides into the atmosphere that migrated throughout the entire Northern Hemisphere and penetrated the equator down to the South Pole. Luckily, the catastrophe led to relatively low radiation doses overall for the global civilian population, but higher doses occurred with the over 240,000 terribly managed liquidators (cleanup workers), with 134 diagnosed with ARS resulting in 28 deaths. To date, a large increase (thousands) in the incidence of thyroid cancer has occurred among survivors who were young children and adolescents at the time of the accident and lived in the most contaminated areas. Since the Soviet government did not inform the population for three days after the accident, these exposed young people did not receive iodine protective pharmaceuticals until they were no longer useful. Secondary thyroid cancers, leukemia, and cataracts are still being monitored. $^{52}$

Coming out of this catastrophe, mental health impacts are regarded as the largest public health problem. The most severe acute and long-term health consequences in the civilian population are psychological with widespread high levels of stress, anxiety, overuse of alcohol, unexplained physical symptoms, and violent behaviors and suicides. ${ }^{52}$ Fighting the panic and mass hysteria could be regarded as the most important countermeasure to protect the public should a similar accident occur.

This study pulls from the work of the IAEA Response and Assistance Network (RANET) Field Assistance Teams, which represent "technically qualified and equipped personnel that may be called upon to provide in situ assistance in a requesting nation-state." ${ }^{53}$ Personnel must have competence and experience in radiation medicine, emergency medicine, disaster medicine (eg, mass casualties), and other related areas (eg, hematology, burn treatment, physical and biological dosimetry, bioassay). Additionally, the External Base Support assets are not deployed but may be called upon to provide advice on monitoring and recording of prodromal signs and symptoms, consultation in relevant medical specialties (eg, hematology, burn treatment, surgery, nuclear medicine, radiotherapy, and psychology), and advice on sampling procedures (eg, repeated blood cell counts, biodosimetry, bioassay). ${ }^{53}$

Moreover, based on common lessons learned from responses to previous nuclear or radiation events and the Fukushima 


\section{TABLE 2}

\section{Major Public Health Challenges in Responding to Nuclear Events}

- Limited capacity and availability of radiation health experts for monitoring potentially exposed people for radioactive contamination.

- Limited mobilization, recruitment, training, and valid exercises of the very large numbers of medical and public health personnel required for nuclear event response, especially for nuclear weapon use.

- Lack of the utility, training, and understanding of the feasibility of radiation decontamination among health care facilities and health responders.

- No public health authority to detain people contaminated with radioactive materials.

- Limited public health and medical capacities for a coordinated response to nuclear weapon medical response.

- Need to improve public health communications and response for the unique aspects of radiation-related mass events.

- Lack of uniformity in national and international exposure standards for radiation measurements (and units) and protective action guidelines.

- Limited access to timely radiation emergency monitoring data.

- Current distribution potential for potassium iodide (KI) in response to airborne radioiodine not likely to meet narrow window of effective distribution (no later than 4 hours after exposure).

- Lack of timely access (or knowledge) concerning highly effective approved and experimental radioprotectant drugs.

- Lack of knowledge and training with approved and stockpiled thermal burn treatments ideal for mass casualty burn applications.

- Lack of knowledge of rapid questionnaire for radiation exposure triage generated from Chernobyl highly exposed worker experience.

- Lack of knowledge of health care workers for environmental radiation effects versus medical radiation use, myths and realities of radiation exposure, and likely outcomes of a health care response, as judged by recent surveys.

experience, ${ }^{54}$ Table 2 lists the major public health challenges identified that may not be adequate at the time of a large-scale radiological incident.

\section{Nuclear War}

In 1984, at the height of the Cold War, WHO's study on the global health repercussions of nuclear war concluded that the immediate and delayed loss of human and animal life would be enormous and "the plight of survivors would be physically and psychologically appalling." tional Committee of the Red Cross and UN agencies asserted "that a nuclear attack anywhere in the world would overwhelm the health infrastructure, making an effective humanitarian response impossible. Those attempting to provide relief to the sick or wounded would be exposed to high levels of radioactivity, risking their own lives. Nowhere in the world would it be possible to render an effective humanitarian response, underscoring the absolute imperative of nuclear abolition." WHO concluded that "the only approach to the treatment of the health effects of nuclear explosions is primary prevention of such explosions." ${ }^{55}$ In 2011, Coleman et $\mathrm{al}^{56}$ asserted that "thoughtful planning is not futile and can substantially mitigate health consequences of a nuclear attack," citing "never ending new technologies, diagnostics, medical countermeasures, resource-sharing models" and a myriad of advanced knowledge and tools from the medical and physical sciences.

The health outcomes for an urban nuclear detonation would fall into 3 primary categories: trauma, thermal burn, and radiation..$^{57}$ In all 3 categories, the very large number of victims leads to a total inadequacy of health care response (and hence a major source of denial in the medical and public health community); the lack of familiarity with victims of environmental radioactivity in the medical experience of virtually all providers becomes particularly problematic for treatment.
For the production of trauma injuries, a shock wave accompanies the pressure change that results in the destruction of buildings, causes damage to eardrums and other structures in humans, and results in the intense movement of massive amounts of debris. ${ }^{58}$ The destruction of buildings and the movement of materials within the shock wave can be expected to generate very large numbers of trauma injuries, amounting to hundreds of thousands of trauma patients in a densely populated urban area for a large nuclear weapon, although much smaller numbers would result from a $10-15 \mathrm{kT}$ device expected to be used by the newer nuclear powers. ${ }^{59}$

Owing to the intense demand on medical personnel in treatment, the large number of thermal burn injuries will be daunting to address in mass casualty response to a nuclear detonation. Thermal burn injuries, which would occur immediately after the detonation (resulting in both fatalities and survivors), should be distinguished from radiation burns, which will not appear until hours and days after the event. $^{60}$ The large release of radiant heat as well as the generation of many fires in the blast area will cause a large number of thermal burn victims, which will create one of the most perplexing logistical medical issues in a nuclear weapon response. ${ }^{61}$ With the detonation of a large nuclear weapon in a major urban area, more than 100,00 serious but survivable burn victims could need to be managed by the medical response community. ${ }^{62}$ Fortunately, the number of thermal burn victims is dramatically less for the smaller nuclear devices $(10-15 \mathrm{kT})$, which are generally expected to be the more likely weapons to be initially used (according to US Department of Health and Human Services planners)..$^{57}$

Radiation injuries in nuclear detonations result from both immediate and delayed radiation exposure. Gamma 
irradiation is released in a single massive burst by the detonation, affecting those in close proximity. Exposures to delayed radioactivity can occur over wide areas secondary to the airborne dispersion of fission products, which condense and return to the ground as what is known commonly as "fallout." The dispersion of fallout is dictated primarily by the prevailing winds in the first days following the detonation. Most of the very high mortality and morbidity results in concentrated areas where the fallout lands in the first 24 hours (early fallout), whereas much lower levels of radioactivity (and much lower risk) will exist over very wide areas. $^{63}$

In considering a planned medical and public health response to nuclear weapon use, it is feasible to predict the likely distribution of the different categories, including degree of severity, of casualties in order to enable rational planning of the response needed and possible with existing resources. ${ }^{59}$ In a timely comparison with the current diplomatic effort relative to the acquisition of nuclear weapons by Iran, Dallas and colleagues ${ }^{64}$ calculated deaths and injuries for various possible plume-based scenarios in a feasible nuclear war between Israel and Iran over the next decade. The 26 devastating scenarios in this study detailed the impact of targeting of compact urban areas in these Middle Eastern nations. It was shown that a devastating loss of critical public health infrastructure and enormous social chaos, rapid eradication of communications, transportation, security, fire-fighting, ambulances, hospital systems, and personnel would kill more people directly and indirectly in a matter of hours in both nations than occurred in the entire Holocaust. ${ }^{64}$

The consideration of a rational approach to health management of a nuclear war would involve planning for treating casualties with ARS, trauma injuries, thermal burns, and combined injuries and patients with radionuclide contamination. ${ }^{65}$ Depending on the territory and landscape, any major nuclear crisis would probably see all degrees of ARS health consequences and outcomes. While massive numbers would die from burns and traumatic injuries in these "death zones," many of those in the "injury zones" would survive the initial blast with grievous traumatic wounds, lacerations, orthopedic injuries, and second- and third-degree thermal burns. Without immediate expert treatment, the injury zones would also become death zones with death from overwhelming infections and shock resulting from lack of treatment. ${ }^{64}$

One key conclusion in nuclear war health management is that owing to the high degree of effort currently necessary in emergency thermal burn care (eg, the high ratio of medical personnel to burn patients, and the need for sterile conditions), it is highly unlikely that these thousands of burn victims will receive any meaningful medical treatment. Even with the unlikely scenario that health facilities remain intact and all health care workers survive and respond, existing health care systems will not have the capacity to deal with the catastrophic number of victims. At best, there will be over 1000 critical victims for each surviving physician. Unless a dramatic change is made in the organization of the medical and public health response to nuclear war, the thousands of thermal burn victims will receive little to no care, as the very limited surviving medical resources are most likely to be devoted to the trauma casualties, which are more familiar to medical personnel, require relatively less effort per patient, and achieve more robust outcomes for each patient relative to available resources.

It is known that as nuclear powers expand their nuclear capability over time, they gradually develop higher yields in their weapons. Evidence from nuclear weapon casualty predictions show that the larger weapons play a dramatic role in casualty propagation. Fortunately, it is generally considered that the most likely initial use of nuclear weapons will involve the smaller weapons, for example, a 10-15-kT weapon (Hiroshima-sized), which is the domain of the relatively younger nuclear powers (North Korea, Pakistan, Iran) that might be considered more likely to use these weapons in the near future (Figure 3). In US emergency planning, the planning scenario (one of 15) that deals with a nuclear detonation assumes a $10-\mathrm{kT}$ detonation as the most likely to occur. ${ }^{57}$ Therefore, emergency planning for a nuclear global health workforce could reasonably adopt this as a planning goal as well, in order to provide a reasonable hope of accommodating a response. Once initial planning and response for this smaller weapon size has progressed, an expansion to larger weapon responses could be envisioned. Planning for the smaller weapon use would also help significantly in dealing with the denial issue, as progressing toward what is considered an "achievable" goal would enable the effort to at least begin in earnest.

\section{POPULATION EVACUATION}

Distinct to nuclear reactor and nuclear war scenarios are the massive number of evacuees and the major and often unexpected demands produced. Timely evacuation decisions are essential to all health and logistics outcome parameters but also bring new health challenges. Decisions to evacuate at-risk populations must be made within hours, but plans for and criteria to evacuate are lacking. Within a few weeks after the Chernobyl accident, more than 116,000 persons were evacuated from the most contaminated areas of Ukraine and Belarus. Another 230,000 people were relocated in subsequent years. Thousands continue to live in areas classified by Ukrainian and Belarussian authorities as strictly controlled zones, where chronic radioactive cesium contamination remains a problem. ${ }^{52}$ The day after the Fukushima earthquake and tsunami, over 210,000 people were evacuated from areas surrounding the nuclear plant due to release of radioactive elements into the environment. On day 3, an additional 180,000 people living within $20 \mathrm{~km}$ of the plant were evacuated and those living beyond the $20 \mathrm{~km}$ and up to 
FIGURE 3

Global Nuclear Weapons.

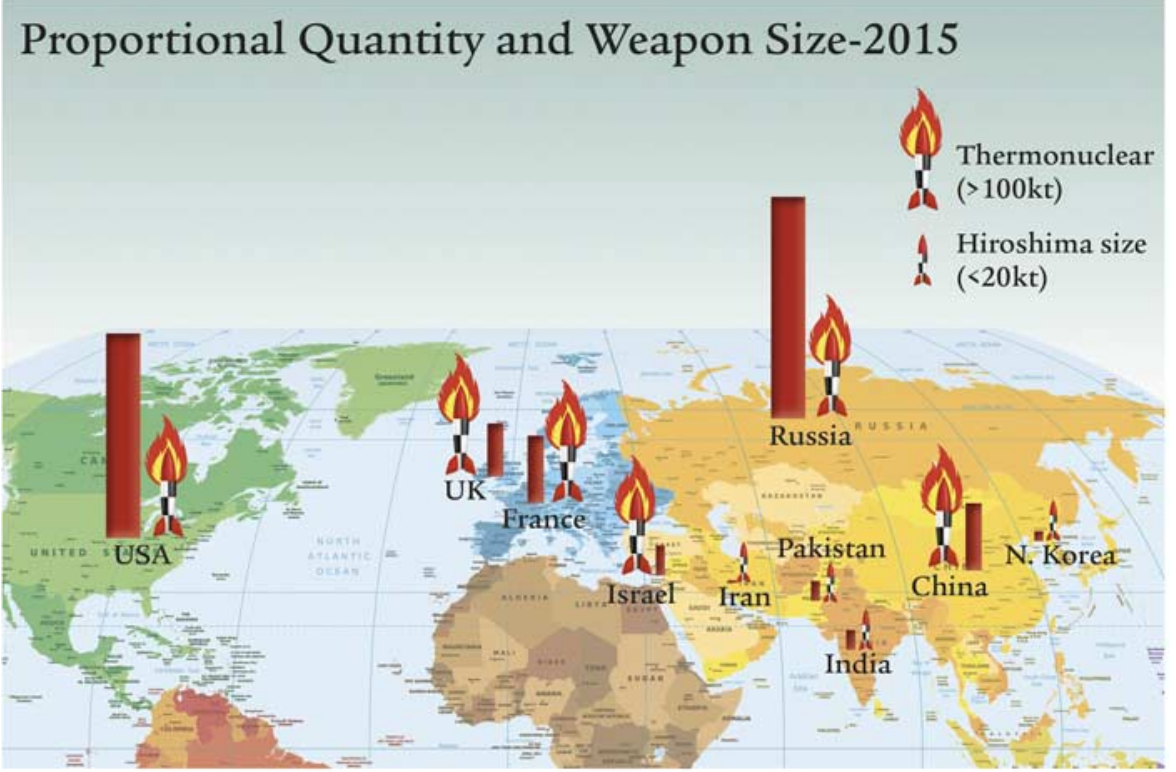

Depiction of the global capacity and capability of nuclear weapon arsenals to produce significant medical and public health crises. The vertical bars represent by volume the relative number of nuclear weapons of all sizes for each nation. Six nations have large thermonuclear devices ( $>100 \mathrm{kT}$ ) which produce a much larger number of trauma and radiation casualties than the Hiroshima-sized devices $(<20 \mathrm{kT})$, the latter being the domain of nations in the initial stages of nuclear weapon development and expansion. Very significant for medicine and public health is that these thermonuclear devices produce very large numbers of thermal burn casualties, the "Achilles heel" of health care systems worldwide that risk overwhelming any existing global health care system.

$30 \mathrm{~km}$ were advised to remain indoors. The government's worst-case scenario called for the evacuation of over $500,000 .^{66}$ The evacuation process was severely plagued by misinformation, inadequate and confusing evacuation orders, delay in releasing information, stranded elderly and infirmed being left in areas near the plant, poor treatment and placement of hospitalized patients, and some evacuees being sent to higher dosed areas, all leading to loss of public trust in the government and poor compliance. ${ }^{66-68} \mathrm{Wilson}^{69}$ argues that the reaction was incorrect and detrimental to public health, citing that the risks of unnecessary evacuation exceeded the risk of radiation cancers hypothetically produced by staying in place. This was not realized by those who had to make a decision within hours; arguing strongly for immediate international guidelines for both evacuation criteria and "important changes in radiation protection." ${ }^{, 69}$

A high-yield nuclear war would bring evacuation numbers to incomprehensible levels. However, new evidence has altered previous dire predictions in low-yield nuclear blasts. The United States has limited evacuation in their planning after a low-yield (10 kiloton) nuclear bomb, emphasizing in a Washington, DC, scenario that despite 100,000 fatalities and about 150,000 casualties, the blast plume would be confined to a relatively small area. People upwind would not need to take any action and those sufficiently downwind would not move other than to seek "moderate shelter."70 These considerations point to a continued reasonable expectation that a viable response could be envisioned for the nuclear global health workforce to respond to nuclear weapon attack, starting initially with the most likely scenario of a relatively small weapon in the Hiroshima-size range.

\section{IS A NUCLEAR GLOBAL HEALTH WORKFORCE A VIABLE OPTION?}

Despite the gloomy prospects of the health outcomes of any large-scale nuclear event common in the minds of many, it is both mankind's nature and moral and ethical obligation to respond to any and all PHEICs. Cutting through the global denial that can exist in many humanitarian crises, humanitarian providers have taken the painful incremental steps, often brought about by awareness that most health and other providers do see themselves as global citizens, to accept increasing global health and security obligations (eg, SARS, Ebola, Chernobyl). The case is made here that the consequences of the most likely initial nuclear event (ie, a smaller Hiroshimasized device) will enable the formation of a nuclear global health workforce for initial planning and organization. 
One can draw historical analogies to the state of the UN humanitarian agencies during the Cold War and that of UN nuclear agencies today. From 1945 to 1990 was a period during which US and Soviet representatives to the UN's Security Council "would frequently veto aid missions to areas on either side of the capitalism/communism divide" leading to indefensible UN noninterventions. ${ }^{71}$ However, during those years, UN agencies (eg, UNHCR, UNICEF) designed plans and developed standards for humanitarian response (eg, refugee camp design, legal protocols, staffing requirements) but these talents were rarely put to use. In 1991 and the end of the Cold War, the Security Council voted to provide humanitarian aid for the Kurdish Crisis in northern Iraq. Because the UN agencies had no operational capacity, the UN asked member states to assist the Kurds. Within 48 hours, the United States, the United Kingdom, and militaries from several Gulf War allies defended the fleeing Kurds and furnished "direct assistance" (protection/security, logistical, transport, communications, and some emergency health care) until it was safe for the humanitarian community to take over. A similar Security Council debate and action would occur with any nuclear exchange. The IAEA and WHO's REMPAN, with experiences in radiation overexposure and nuclear plant accidents, are prepared to provide the legal framework, requisite concept of operations, functional area detailed protocols and worksheets, a compatible and integrated system for the provision of international assistance, and standards for any technical and health response and resources required. While many of these products serve as models adapted to a larger-scale PHEIC resulting from a nuclear exchange, these agencies lack the coordinated and collaborative response capabilities and the variety of operational professional staffing elements.

For example, GOARN serves as a technical collaboration of existing institutions and networks that pool human and technical resources for rapid identification and confirmation for outbreaks of international importance. Recognized now as an independent body under the $\mathrm{WHO}$, it provides an operational framework to link this expertise and skill sets to keep the international community constantly alert to the threat of outbreaks. GOARN does not claim extensive nuclear expertise; however, in any nuclear crisis, life-saving infectious disease, immunology, and sterile environment skill sets that are essential to GOARN will also be crucial in providing care to burn and trauma survivors who will be at greater risk of secondary infections and radiation-induced immunity problems. This will only be realized with a formal, well-coordinated and collaborative professional relationship with a similar global workforce from the nascent nuclear community. Similarly, advances in the Global FMTs Registry sets minimum standards for international health workers ready for deployment that clearly outline their services and skills for a bevy of humanitarian crises. The FMT initiative coordinated over 60 governmental and INGO FMTs deployed during the Ebola epidemic, and 132 FMTs, an additional 15 military teams, and 75 local and international urban search and rescue teams responded to the 2015 Nepal earthquake tragedy, a capability and capacity not previously seen in PHEICs.

In calling for an authority for crisis coordination and accountability for humanitarian crises in 2011, Burkle and colleagues $^{72}$ cited the potential of the 2005 IHR that obliges the WHO to obtain expert advice on any declared PHEIC, emphasizing that the success of the IHR, and its language, opens the door for potential international cooperation wider where similar models of response can be introduced. While the Ebola tragedy exposed the subsequent weaknesses of the WHO response capacity, it is encouraging that today fertile discussions are taking place that would strengthen WHO staffing and resources as well as the properties and resources of GOARN, FMTs, and urban search and rescue assets. In calling for a global health emergency workforce, it is timely that equal emphasis be brought to bear on the formation of a nuclear global health workforce, one that would provide an operational framework worthy of the technical expertise of the IAEA and the WHO. Experiences with radiation overexposure and nuclear plant accidents reveal the critical concept of operations and potential national assistance and response capabilities within IAEA and WHO leadership. Extensively detailed protocols and worksheets serve as models for what could be adapted to larger-scale PHEIC-coordinated responses. Admittedly, there remain major gaps in coordination, collaboration, resource sustainability, and the education and training of available global health professionals.

Looking at this question from a health outcomes perspective, the very high casualty outcomes in nuclear war pose an extreme dilemma for those planning and executing any medical response, which understandably, often results in despair and denial. ${ }^{73}$ The first response would be to assume that any efforts at planning and response would not be productive. However, as predictive studies of nuclear war medical casualties have shown, the many variations in nuclear war (as in all warfare) shows sufficient heterogeneity that allows for potentially effective changes in the strategy of the utilization of resources based on variations such as the approximate geographic distribution of casualties and the mobilization of specific medical professions to meet these needs. These are particularly achievable goals in responding to the relatively smaller nuclear weapons as illustrated in the simulation study. ${ }^{64}$ Knowledge of the location of trauma victims is highly useful in planning of patient transport, especially in an effective emergency response system. For both large and relatively smaller nuclear weapons, predictions of the distribution of radiation casualties is essential to planning and response for the decontamination of these patients before transport and for the prevention of contamination of rescue teams and planning of where to send the limited number of teams to both protect them and use them most efficiently. ${ }^{64}$ 
The location of accessible numbers of trauma victims from broken glass on the periphery of the blast zone is another example of a casualty distribution that is a favorable prediction for productive action for both smaller and larger nuclear weapons. In this manner, it can be a source of hope to be able to plan and respond in selected areas identified by predicted casualty distributions. Also, trauma injuries are familiar to all emergency medical professionals, and therefore provide a focal point to beginning a rational response to expanding that response to the scale envisioned for a relatively smaller nuclear weapon. To enable this expansion of scale to the very large medical response demands of nuclear war, the mutual aid of other countries would be enlisted, specifically among worldwide medical and surgical assets, and existing FMT and urban search and rescue assets, to allow productive, strategic planning and proper resource distribution. The extensive use of ship and aeromedical transport would be greatly expedited with prior planning and mutual aid staffing and funding agreements with the $\mathrm{WHO}$ and their operational components. Admittedly, while FMTs do have skills in trauma and basic burn care, with the current limited knowledge base of radiation risk it is understandable there would be concerns about the short- and long-term risks and similar hesitancies would exist, many seen with the Ebola epidemic, that would understandably be present with a radiation tragedy limiting FMT deployment. However with extensive preparedness education and training, and guided by estimates (verified over time) of casualty distributions and locations at the time of a nuclear blast, it could be made sufficiently safe for the dispatch of rescue teams and the air transport itself (by avoiding radiation zones, traffic barriers, and security issues), and provide a better chance for getting certain patient categories to the air transport in time to actually save lives. A lower-tech approach involving training armies of nonspecialists in surgical debridement from heavily sedated patients and administration of burn medicines would provide many of those in the "injury" zones the best opportunity for survival. ${ }^{64}$

A most convincing argument comes from both recent and archival studies on definitive survivability of medical casualties that make the same point over time. Given advances in standards of care, mass casualty burn victim strategies, and triage approaches, the central theme and common assumption of all is that many measures leading to survivability can be approached, if not solved. ${ }^{56,74-85}$

It must be emphasized that no one country has the medical and organizational assets to manage a nuclear tragedy alone. A PHEIC by definition will always require a robust international response. It is proposed that a nuclear global health workforce be developed from a similar hybrid of untapped professional nuclear technical and health assets incorporated in partnership with future WHO-supported preparedness training of potential deployable teams. This initiative would be supported by a large network of INGOs, the Global Health Security Agenda, and other UN bodies covered under existing WHO and IHR mandates and the appropriate political and diplomatic mutual aid arrangements in advance of nuclear war and mass casualty surge planning. Because of the nature of the crisis and where expertise currently lies, expertise will come from a myriad of civil, military, and private assets. However, while conventional wisdom may suggest that the military have robust operational capability, especially in those countries that deploy nuclear weapons, in fact this capability is relatively minor and less than the public may believe. Overall civil and military willingness to be deployed will depend on evidence-based residual risk and safety data. Lastly, a workforce-directed and WHO-supported robust education and training program is vital and constructed on global consensus of scenario-based scientific evidence, best clinical and public health practices, and sound professional and policy principles.

\section{PROPOSED NUCLEAR WORKFORCE FRAMEWORK}

The workforce framework would include medical support to triage, care to those with the opportunity to survive, and palliative care to the expectant population as well as the lessaffected populations and those evacuated to safer ground. Ongoing support for scarce resource allocation and ethical decision-making to best mitigate both direct and indirect mortality and morbidity is vital. ${ }^{74-77}$ This would require capability and capacity for the following.

\section{Nuclear Triage Centers}

The requirements would be for centrally coordinated mobile and fixed initial triage and dose-monitoring facilities designed to identify, assess, transfer, decontaminate, and move casualties efficiently to survivor or palliative care facilities. Patients will have various degrees of ARS, combined injuries, local radiation injuries, and radionuclide contamination. Early research suggests that clinical symptoms and hematological indicators alone fall short for initial critical triage decisions. While admittedly clinical presentation should determine the "priority and nature of treatment," ${ }^{, 78}$ first-line triage in nuclear triage centers would be best supported by additional and "fast biological dosimetry" designed for the purpose of triage. ${ }^{86}$ Biodosimetry has been considered most accurate in determining "probability of fatality" and less so on "severity of injury."78 Serial secondary triage in rearward treatment facilities would focus on clinical, serial hematological and other advanced biological parameters (eg, protein biomarkers for better triage accuracy than one biomarker alone). ${ }^{78,87}$

Triage decisions will optimize opportunities for both direct casualty care and mitigation of indirect or preventable mortality and morbidity. Well researched triage tools and cards leading to treatment guidance are readily available. Triage is an ongoing process, never a onetime event. Primary and secondary triage decisions will normally fluctuate as assessments and system-wide resources become available. Professional staffing recommendations (Table 3) derived 
Field-Based Centers Under the Nuclear Global Health Workforce ${ }^{a}$

\section{Nuclear Triage Centers}

- RANET's mission assets: triage, biodosimetry/bioassay teams

- Medical triage support teams: radiation medicine, emergency physicians/disaster medicine, nurse practitioners, EMS personnel, and emergency managers

- Multidisciplinary specialists to advise and provide triage consultation

- Psychiatrists/psychologists

- Radiation safety officers

- Nuclear preventive medicine and public health experts: surveillance and data gathering

- Civil-military coordinators: logisticians, security, transportation, communications, resource managers

- Religious/cultural/legal experts/translators

- Coordinators for casualty referrals

\section{Nuclear Survival Centers}

- Entry-Level secondary triage team: emergency physicians, nurse practitioners, triage resource managers

- Secondary biodosimetry/bioassay teams

- General, burn, trauma, ophthalmologic, and orthopedic surgeons

- Radiologists, radiation oncologists, nuclear medicine, and radiation safety officers

- Hematologists, gastroenterologists, clinical toxicologists, pediatricians

- Infectious disease/immunology/sterile environment assets

- Anesthesia/critical care/pain management

- Rehabilitation medicine: crisis-trained debridement professionals

- Acute and chronic care nurses and nurse practitioners: surgery, burn, critical care

- Hospital-level ward and isolation nurse staffing; general nursing and paramedics, unit administrators

- Pharmacists

- Primary health care specialists: internal medicine, pediatrics, family medicine

- Preventive medicine and public health experts: surveillance and data gathering

- Mental health professionals and family counselors

- Cross-trained optometrists, veterinarians, dentists

- Religious/cultural experts/translators/information management professionals/anthropologists

- Civil-military coordinators: logisticians, security, transportation, communications, nuclear technicians and managers.

- Coordinators for deployable FMTs

\section{Nuclear Palliative Care Centers}

- Hospice/palliative care nurses and nurse practitioners

- Primary care physicians and nurses

- Physician anesthesiologists/nurse anesthetists, and pain management experts

- Mental health assets: psychiatrists/psychologists

- Family counselors

- Burial services personnel and assets

- Religious/cultural/legal experts/information management/anthropologists

- Preventive medicine and public health experts: surveillance and data gathering

- Pharmacists

- Civil-military coordinators: logisticians, security, transportation, communications

- Coordinators for deployable FMTs

Health System Support Centers

- Hospital- and clinic-based primary health care physicians and nurses

- Hospital-based subspecialists

- Preventive medicine and public health experts: surveillance and data gathering

- Mental health and social work professionals and services, anthropologists

- Essential public health infrastructure monitoring teams: water, sanitation, food, health access and availability, shelter and energy

- Radiation monitoring team surveillance and education teams

- Coordinators for deployable FMTs

${ }^{a}$ Abbreviations: EMS, emergency medical services; FMT, foreign medical team; RANET, Response and Assistance Network.

from IAEA/RANET and REMPAN recommendations include both primary and supporting elements.

\section{Nuclear Survival Centers}

The requirements would be for fixed/hospital-based facilities to optimize survival opportunities and mitigate secondary indirect mortality and morbidity. Professional staffing (Table 3) would include both primary and supporting elements.

\section{Nuclear Palliative Care Centers}

The requirements would be for both fixed and mobile facilities to provide palliative care including pain relief/management, 
social, psychological, family, and burial support services. Professional staffing (Table 3) would include both primary and supporting elements, including trained volunteer staff and support services from the surrounding communities and national governments.

\section{Health System Support Centers}

The requirements for populations in unaffected zones and evacuees are to recover, restore, rehabilitate, and sustain essential public health infrastructure and health systems and to ensure both availability and access to health care in mitigating indirect mortality and morbidity. This includes the monitoring of vulnerable population indicators, including noncommunicable diseases. The health system support centers would be the primary area for FMTs and other health- and non-health-related INGOs and IOM. The global health workforce would provide supplemental care through pre-crisis-identified NGOs, FMTs, and indigenous health care volunteers, who have experience in refugee and internally displaced population care. Staffing (Table 3) in both fixed and mobile facilities would supplement indigenous health system personnel as well as staff new facilities for the evacuated populations.

Estimations would be made of the likely professional group categories and their respective numbers and ratios that would be needed. Crossover applications of capabilities that also apply to nuclear global response efforts, such as surge capacity in beds and nurse-to-bed ratios and the transfer of previously existing patients out of the nuclear/radiation areas to increase surge capacity without increasing the morbidity or mortality of either the previous or the new patients. For example, these disasters require ophthalmologists and cross-trained optometrists for casualties resulting from extensive broken glass zones (extending far beyond the trauma zone even for the relatively smaller nuclear weapons), rehabilitation-medicine-trained wound and burn debridement specialists and veterinarians for similar debridement and wound closure following mass casualty trauma, and information technology technicians to rig emergency medical communication between the various care centers, evacuation camps, and other field applications, to name but a few.

\section{CONCLUSIONS}

Many factors have contributed to the escalating threat of a major nuclear crisis, which would immediately result in an unprecedented PHEIC, leading to massive numbers of direct and indirect morbidity and mortality. However, health outcomes research supports that life-saving opportunities are possible, even after a major nuclear war, but only if a robust multidisciplinary response capability and capacity was developed. Whereas the IAEA and WHO assets currently provide field-level guidelines, nuclear triage and management plans, worksheets and technical (eg, bioassay and biodosimetry) monitoring standards required for radiation overexposures and nuclear plant accidents, it lacks the operational leadership for a coordinated and collaborative effort demanded of a large-scale nuclear crisis such as a nuclear weapon exchange. This study argues for the development of a nuclear global health workforce: one that brings together nuclear and nonnuclear technical and health professionals to educate and train in partnership with an IHR mandate and the WHO to meet the preparedness, coordination, collaboration, and staffing requirements necessary for a large-scale nuclear crisis response.

\section{About the Authors}

Harvard Humanitarian Initiative, Harvard School of Public Health, Cambridge, Massachusetts, and Woodrow Wilson International Center for Scholars, Washington, DC (Dr Burkle), and Institute for Disaster Management, Department of Health Policy $\mathbb{E}$ Management, College of Public Health, University of Georgia, Athens, Georgia, and Department of Emergency Medicine, Medical College of Georgia, Georgia Regents University, Augusta, Georgia (Dr Dallas).

Correspondence and reprint requests to Frederick M. Burkle, Jr, MD, MPH, Harvard Humanitarian Initiative, 14 Story Street, 2nd Floor, Cambridge, MA 02138 (e-mail: fburkle@hsph.harvard.edu).

Published online: November 3, 2015.

\section{REFERENCES}

1. Mackenzie JS, Drury P, Arthur RR, et al. The Global outbreak alert and response network. Glob Public Health. 2014;9(9):1023-1039.

2. Inter-Agency Standing Committee, Global Health Cluster. Concept paper: foreign medical teams. http://www.who.int/hac/global_health_ cluster/about/policy_strategy/fmt_concept_paper_16may11.pdf. Published May 17, 2011. Accessed June 26, 2011.

3. Burkle FM. Global health security demands a strong International Health Regulations Treaty and leadership from a highly resourced World Health Organization. Disaster Med Public Health Prep. 2015;9(5): 568-580.

4. World Health Organization. Ten things you need to know to implement the IHR. Alert, response, and capacity building under the International Health regulations (IHR). http://www.who.int/ihr/about/10things/en/. Accessed April 29, 2015.

5. World Health Organization. Executive Board, Special Session on Ebola, Provisional agenda item 9.4, EB136/49, 9 January 2015. http://apps.who.int/ gb/ebwha/pdf_files/EBSS3/EBSS3_3-en.pdf. Accessed January 15, 2015.

6. Heymann D. Development of a Plan for a Stronger Global Health Emergency Workforce. Friends of the Resolution, Second meeting, 9 April 2015. http://www.who.int/about/who_reform/emergency-capacities/ Global-health-emergency-workfoce.pdf. Accessed May 4, 2015.

7. Green WG III, McGinnes SR. Thoughts on the higher order taxonomy of disasters. Notes on the Science of Extreme Situations, paper no. 7. https://facultystaff.richmond.edu/ wgreen/paper7.pdf. Updated July 11, 2006. Accessed December 10,2007.

8. Burkle FM Jr, Greenough PG. Impact of public health emergencies on modern disaster taxonomy, planning, and response. Disaster Med Public Health Prep. 2008;2(3):192-199.

9. WHO. Effect of Nuclear War on Health and Health Services, 2nd ed. Geneva: World Health Organization; 1987:24-28.

10. National Security Staff Interagency Policy Coordination Subcommittee for Preparedness and Response to Radiological and Nuclear Threats. Planning Guidance for Response to a Nuclear Detonation. 2nd ed. http:// www.remm.nlm.gov/PlanningGuidanceNuclearDetonation.pdf. Published June 2010. Accessed October 20, 2015. 
11. Burkle F Jr, Garfield R. Civilian mortality after the 2003 invasion of Iraq. Lancet. 2013;381(9870):877-879.

12. Burkle F Jr, Martone G, Greenough PG. The Changing face of humanitarian crises. The Brown Journal of World Affairs. Spring/Summer 2014;XX(11):26-42.

13. Kaysen C, McNamara RS, Rathjens GW. Nuclear weapons after the Cold War. Foreign Affairs. Essay, Fall 1991 issue. https://www.foreignaffairs. com/articles/1991-09-01/nuclear-weapons-after-cold-war. Accessed April 12, 2015.

14. Arms Control Association. Nuclear weapons: who has what at a glance. Fact Sheets \& Briefs. http://www.armscontrol.org/factsheets/Nuclearweapons whohaswhat. April 2015. Accessed April 4, 2015.

15. Federation of American Scientists. Status of World Nuclear Forces. http://www.armscontrol.org/factsheets/Nuclearweaponswhohaswhat. Accessed April 12, 2015

16. International Panel on Fissile Materials. Country Perspectives on the Challenges to a Fissile Material (Cutoff) Treaty. http://fissilematerials. org/library/FMCT-Perspectives.pdf. Accessed April 4, 2015.

17. Federation of American Scientists. Weapons of Mass Destruction. WMD Around the World. http://fas.org/nuke/guide/iraq/nuke/program.htm. Accessed April 4, 2015.

18. IAEA. Monitoring and Verification in Iran: March 2015. https://www. iaea.org/newscenter/focus/iran. Accessed March 5, 2015.

19. Homeland Security News and Information. Suitcase nukes. http://www. nationalterroralert.com/suitcasenuke/. Accessed May 1, 2015.

20. Nuclear Safety \& Security: 'Dirty bomb' threat. IAEA website. http:// www-ns.iaea.org/security/dirtybombs.asp?s=4. Accessed 1,May 2015.

21. Dahl F. Missing radioactive material may pose 'dirty bomb' threat: IAEA. Reuters: World. http://www.reuters.com/article/2014/03/21/us-nuclearsecurity-iaea-idUSBREA2K10W20140321. Published March 21, 2014. Accessed May 1, 2015.

22. Schneider M, Froggatt A, Ayukawa Y, et al. The World Nuclear Industry Status Report 2014. http://www.worldnuclearreport.org/WNISR2014. html. Published August 18, 2014. Accessed April 28, 2015.

23. Rogers K. Scientist predicts another major earthquake in Japan by 2017. JAPANTODAY. http://www.japantoday.com/category/national/view/ scientist-predicts-another-major-earthquake-in-japan-by-2017. Published August 3, 2014. Accessed April 28, 2015.

24. World Nuclear Association. Nuclear Power in Japan. http://www.worldnuclear.org/info/Country-Profiles/Countries-G-N/Japan/. Updated April 25, 2015. Accessed April 29, 2015

25. World Economic Forum. Energy Vision 2013: Energy Transitions: Past and Future. http://www3.weforum.org/docs/WEF_EN_EnergyVision_ Report_2013.pdf. Published January 2013. Accessed 19 April 2015.

26. Shermer M. Will mutual assured destruction continue to deter nuclear war? Scientific American. http://www.scientificamerican. com/article/will-mutual-assured-destruction-continue-to-deter-nuclear-war/. Published June 1, 2014. Accessed April 14, 2015.

27. Alpha History: Nuclear Weapons. http://alphahistory.com/coldwar/ nuclear-weapons/. Accessed April 11, 2015.

28. Hamilton R. Topic Analysis. Nuclear Weapons. Resolved: States ought not possess nuclear weapons. http://www1.dcsdk12.org/secondary/dchs/ docs/131504.pdf. Accessed April 10, 2015.

29. Arms Control Association. The Cuban Missile Crisis. http://www. armscontrol.org/print/1144. Accessed April 10, 2015.

30. Tannenwald N. Nuclear weapons and the Vietnam War. The Journal of Strategic Studies. 2006;29(4):675-722. http://www.watsoninstitute.org/ pub/vietnam_weapons.pdf. Accessed April 10, 2015.

31. Masco J. The Nuclear Borderlands: the Manhattan Project in Post-Cold War New Mexico. Chapter 1: The enlightened Earth. Princeton University Press; 2006. http://press.princeton.edu/chapters/s8185.html. Accessed April 12, 2015.

32. Conca J. The nuclear weapons states: who has them and how many. Forbes. http://www.forbes.com/sites/jamesconca/2014/09/25/the-nuclearweapons-states-who-has-them-and-how-many/. Published September 25, 2014. Accessed April 2015.

33. Sagan SD. Policy: A call for global nuclear disarmament. Nature. 2012:487:30-32.
34. Burkle FM Jr. Antisocial personality disorder and pathological narcissism in prolonged conflicts and wars in the 21st century. Disaster Med Public Health Prep. Published online Oct 2015. doi: 10.1017/dmp.2015.113.

35. Singh VK, Romaine PL, Seed TM. Medical countermeasures for radiation exposure and related injuries: characterization of medicines, FDA-approval status and inclusion into the strategic stockpile. Health Phys. 2015;108(6):607-630.

36. Muslim Public Affairs Council. Islamic views regarding terrorism and suicide. http://www.mpac.org/programs/anti-terrorism-campaign/islamicviews-regarding-terrorism-and-suicidem.php. Accessed April 9, 2015.

37. Potter WC, Lewis J. Cheap and dirty Bombs. Foreign Policy. http:// foreignpolicy.com/2014/02/17/cheap-and-dirty-bombs/. Published February 17, 2014. Accessed April 9, 2015.

38. Perry DL. Killing in the name of god: the problem of holy war. Markkula Center for Applied Ethics, Santa Clara University. Accessed April 8, 2015.

39. Hammer MF, Redd AJ, Wood ET, et al. Jewish and Middle Eastern nonjewish populations share a common pool of Y-chromosomes biallelic halotypes. Proc Natl Acad Sci U S A. 200;97(12):6769-6774. http://www. pnas.org/content/97/12/6769.full.pdf. Accessed 1 April 2015.

40. Frank J. Sociopsychological aspects of the nuclear arms race. In: Task Force Report 20: Psychosocial Aspects of Nuclear Developments. Report of the Task Force on Psychosocial Aspects of Nuclear Developments of the American Psychiatric Association. Washington, DC: APA; 1982:1-11.

41. Jenkins BM. Will Terrorists go Nuclear? The Rand Corporation Series. http://www.rand.org/content/dam/rand/pubs/papers/2006/P5541.pdf. Published November 1975. Accessed April 15, 2015.

42. Fein E. The sacred weapons. Bulletin of the Atomic Scientists. August/ September 1981:52-53.

43. Dallas CE, Burkle FM Jr. Nuclear war in the Middle East: where is the voice of medicine and public health. Prehosp Disaster Med. 2011; 26(5):383-385.

44. Flynn DF, Goans RE. Nuclear terrorism: triage and medical management of radiation and combined-injury casualties. Surg Clin North Am. 2006; 86(3):601-636.

45. Donnelly EH, Nemhauser JB, Smith JM, et al. Acute radiation syndrome: assessment and management. South Med J. 2010;103(6):541-546.

46. Grammaticos P, Giannoula F, Fountos GP. Acute radiation syndrome and chronic radiation syndrome. Hell J Nucl Med. 2013; 15(1):56-59.

47. Rea ME, Gougelet RM, Nicolaide RJ, et al. Proposed triage categories for large-scale radiation incidents using high-accuracy biodosimetry methods. Health Phys. 2010;98(2):136-144.

48. Emergency Preparedness and Response: Acute Radiation Syndrome: A Fact Sheet for Clinicians. CDC website. http://www.bt.cdc.gov/radiation/arsphysicianfactsheet.asp. Accessed April 15, 2015.

49. Dallas CE. Medical lessons learned from Chernobyl relative to nuclear detonations and failed nuclear reactors. Disaster Med Public Health Prep. 2012;6:330-334.

50. Coeytaux K, Bey E, Christensen D, et al. Reported radiation overexposure accidents worldwide, 1980-2013: a systematic review. PLoS One. 2015;10(3):e0118709.

51. McGann C, Miaullis A, Page N. Radiologists: the unsuspecting subject matter experts. J Am Coll Radiol. 2015. Apr 15. pii: S1546-1440 (15)00029-0.

52. Health Impacts. Chernobyl Accident Appendix 2. World Nuclear Association website. http://www.world-nuclear.org/info/Safety-andSecurity/Safety-of-Plants/Appendices/Chernobyl-Accident-Appendix2-Health-Impacts/. Updated November 2009. Accessed April 15, 2015.

53. Emergency Preparedness and Response. IAEA Response and Assistance Network. EPR-RANET 2013. IAEA.org website. http://www-pub.iaea. org/books/IAEABooks/10610/IAEA-Response-and-Assistance-NetworkEPR-RANET-2013. Published 2013. Accessed April 7, 2015.

54. Whitcomb RC Jr, Ansari AJ, Buzzell JJ, et al. A public health perspective on the U.S. response to the Fukushima radiological emergency. Health Phys. 2015;108(3):357-363. 
55. International Campaign to Abolish Nuclear Weapons. No adequate response capacity. ICAN website. http://www.icanw.org/the-facts/catastrophic-harm/ lack-of- response-to-a-nuclear-attack/. Accessed April 1, 2015.

56. Coleman CN, Sullivan JM, Bader JL, et al. Public health and medical preparedness for a nuclear detonation: the nuclear incident medical enterprise. Health Phys. 2015;108(2):149-6.

57. Dallas CE, Maliha W, Reeves G, et al. Nuclear and radiological events. In: Swienton R, Markenson D, eds. Basic Disaster Life Support, Version 3.0. Chicago: American Medical Association; 2012.

58. Barnaby S, Rotblat J. Nuclear war: the aftermath: the effects of nuclear war. Ambio. 1982;11:84-94.

59. Dallas CE, Bell WC. Effects of a 10-kt IND detonation on human health and the area health care system: effects on the area health care system. In: Assessing Medical Preparedness to Respond to a Terrorist Nuclear Event. Washington, DC: The National Academies Press; 2009:20-26.

60. Waselenko JK. Medical management of the acute radiation syndrome: recommendations of the Strategic National Stockpile Radiation Working Group. Ann Intern Med. 2004;140:1037-1051.

61. Dallas CE, Bell WC. Prediction modeling to determine medical response to urban attack. Disaster Med Public Health Prep. 2007;1(2):80-89.

62. Postol TA. Possible fatalities from superfires following nuclear attacks in or near urban areas. In: Soloman F, Marston RQ, eds. The Medical Implications of Nuclear War. Washington, DC: National Academy Press; 1986:15.

63. Gonzalez AJ. Radiation protection in the aftermath of a terrorist attack involving exposure to ionizing radiation. Health Physics Society. 2005; 89(5):418-446.

64. Dallas CE, Bell W, Stewart D, et al. Nuclear war between Israel and Iran: lethality beyond the pale. Conflict and Health. 2013;7(1):10.

65. Daugherty W, Levi B, von Hippel F. Casualties due to blast, heat and radioactive fallout from various hypothetical nuclear attacks on the US. In: The Medical Implications of Nuclear War. Washington, DC: National Academy Press; 1986.

66. Facts and Details. Evacuation of the Fukushima area. http://factsand details.com/japan/cat26/sub162/item1752.html. Accessed April 13, 2015.

67. McCurry J. Fukushima nuclear disaster: three years on 120,00 evacuees remain uprooted. The Guardian. http://www.theguardian. com/world/2014/sep/10/fukushima-nuclear-disaster-japan-three-yearsfamilies-uprooted. Published September 10, 2014. Accessed April 13, 2015.

68. Fukushima on the Globe. Evacuation orders and restricted areas. http:// fukushimaontheglobe.com/the-earthquake-and-the-nuclear-accident/ evacuation-orders-and-restricted-areas. Accessed April 13, 2015.

69. Wilson R. Evacuation criteria after a nuclear accident: a personal perspective. Dose Response. 2012;10(4):480-499.

70. Dallas CE. Impact of small nuclear weapons on Washington DC: outcomes and emergency response recommendations. Testimony: US Senate Hearing for the Committee on Homeland Security and Governmental Affairs, April 15, 2008. http://www.google.com/url? $\mathrm{sa}=\mathrm{t} \& \mathrm{rct}=\mathrm{j} \& \mathrm{q}=\&$ \&esrc $=\mathrm{s} \&$ source $=$ web $\& \mathrm{~cd}=2 \&$ ved $=0 \mathrm{CCYQFjAB \& url}=$ http\%3A\%2F\%2Fwww.hsgac.senate.gov\%2Fdownload\%2F041508dallas \&ei=yk9LVeveKsTHogSkzIDADA\&usg=AFQjCNGJjymMtDuyJEC FzuyT-K1bRLM02g\&sig2=YWzBQ8rn5UUm0vQ9JootkQ\&bvm=bv. 92765956,d.cGU. Accessed May 6, 2015.
71. Wood A, Apthorpe R, Borton J. Evaluating International Humanitarian Action. London: Zed Books; 2001.

72. Burkle FM Jr, Redmond AD, McArdle DF. An authority for crisis coordination and accountability. Lancet. 2012;379(9833):2223-2225.

73. Abrams HL, Von Kaenel WE. Medical survivors of nuclear war: infection and the spread of communicable disease. $N$ Engl J Med. 1981;305:1226-1232.

74. DiCarlo AL, Maher C, Hick JL, et al. Radiation injury after a nuclear detonation: medical consequences and the need for scarce resources allocation. Disaster Med Public Health Prep. 2011;5(suppl 1):S32-S44.

75. Coleman CN, Knebel AR, Hick JL, et al. Scarce resources for nuclear detonation: project overview and challenges. Disaster Med Public Health Prep. 2011;5(suppl 1):S13-S19.

76. Knebel AR, Coleman CN, Cliffer KD, et al. Allocation of scarce resources after a nuclear detonation: setting the context. Disaster Med Public Health Prep. 2011;5(suppl 1):S20-S31.

77. Coleman CN, Weinstock DM, Casagrande R, et al. Triage and treatment tools for use in a scarce resources-crisis standards of care setting after a nuclear detonation. Disaster Med Public Health Prep. 2011;5(suppl 1): S111-S121.

78. Armed Forces Radiobiology Research Institute Workshop. GI Reeves, DG Jarrett, et al, eds. Triage of Irradiated Personnel. Proceedings; September 25-27, 1996; Bethesda, MD. http://www.google.com/url? $\mathrm{sa}=\mathrm{t} \& \mathrm{rct}=\mathrm{j} \& \mathrm{q}=\&$ esrc $=\mathrm{s} \&$ source $=$ web $\& \mathrm{~cd}=1 \&$ ved $=0 \mathrm{CCYQFjAA \& url}=$ http\%3A\%2F\%2Fwww.dtic.mil. Accessed May 4, 2015.

79. Flynn DF, Goans RE. Nuclear terrorism: triage and medical treatment of radiation and combined-injury casualties. Surg Clin North Am. 2006; 86(3):601-636.

80. Kumar P, Jagetia GC. A review of triage and management of burn victims following a nuclear disaster. Burns. 1994;20(5):397-402.

81. Bland SA. Masscasualty management for radiological and nuclear incidents. J R Army Med Corps. 2004;159(3 Suppl 1):27-34.

82. Hick JL, Weinstock DM, Coleman CN, et al. Health care system planning for and response to a nuclear detonation. Disaster Med Public Health Prep. 2011;5(suppl 1):S73-S88.

83. Coleman $\mathrm{CN}$, Hrdina $\mathrm{C}$, Bader JL, et al. Medical response to a radiologic/nuclear event: integrated plan from the Office of the Assistant Secretary for Preparedness and Response, Department of Health and Human Services. Ann Emerg Med. 2008;53(2):213-222.

84. Blumenthal DJ, Bader JL, Christensen D, et al. A sustainable training strategy for improving health care following a catastrophic radiological or nuclear incident. Prehosp Disaster Med. 2014;29(1):80-86.

85. Hrdina CM, Coleman CN, Bogucki S, et al. The "RTR" medical response system for nuclear and radiological mass-casualty incidents: a functional Triage-Treatment-Transport medical response model. Prehosp Disaster Med. 2009;24(3):167-178.

86. Ossetrova NI, Sandgren DJ, Blakely WF. Protein biomarkers for enhancement of radiation dose and injury assessment in nonhuman primate totalbody irradiation model. Radiat Prot Dosimetry. 2014;159(1-4):61-76.

87. Deperas-Kaminska M, Bajinskis A, Marczyk M, et al. Radiation-induced changes in levels of selected proteins in peripheral blood serum of breast cancer patients as a potential triage biodosimeter for large-scale radiological emergencies. Health Phys. 2014;107(6):555-563. 